\title{
Measuring customer satisfaction: Evidence from digital library
}

\author{
Zahra Jafarzadeh Kermani $^{\mathbf{a}^{*}}$, Elaheh Tatari ${ }^{\mathrm{b}}$, Gholamreza Sameie ${ }^{\mathrm{b}}$ and Hanieh Motalebipour $^{\mathrm{b}}$
}

${ }^{a}$ Assistant professor, Department of Knowledge \& Information Science, International University of Imam Reza, Mashhad, Iran ${ }^{b}$ M.S student of Knowledge and Information Science in International University of Imam Reza, Mashhad, Iran

\begin{tabular}{l}
\hline C H R O N I C L E \\
\hline Article history: \\
Received January 2, 2015 \\
Received in revised format 6 \\
February 2015 \\
Accepted 24 February 2015 \\
Available online \\
February 26 2015 \\
\hline Keywords: \\
Customer satisfaction \\
Electronic library \\
Graduate students
\end{tabular}

\section{A B S T R A C T}

This paper presents an empirical investigation on user's satisfaction based on the expectation disconfirmation paradigm theory. The study selects a sample of 332 people from 2449 graduate students who were enrolled at the Birjand University. The study uses a questionnaire developed by Isac and Rusu (2014) [Isac, F. L., \& Rusu, S. (2014). Theories of user’s satisfaction and the operationalization of the expectation disconfirmation paradigm. Economic series, university of Targu, 2 (1), 82-88.]. Using path analysis, the study has determined that perceived usefulness and personal experience had the highest impact on users' satisfaction in electronic library usage. In addition, there was a negative relationship between user interface and users' satisfaction.

\section{Introduction}

An electronic/digital library is concentrated on collection of digital objects including scientific journals, books, etc. along with techniques for organizing, storing, and retrieving the necessary files and media contained in the library collection (Marchionini \& Geisler, 2002) Digital libraries (DL) are usually maintained by individuals, firms, or affiliated with established physical library buildings or organizations, or with academic institutions (Akst, 2003). The electronic content of most digital libraries could be stored locally, or accessed remotely through computer networks (Saracevic, 2000; Cunningham et al., 2003). The advantages of DL as a tool for easily and quickly retrieving books, archives and images of different kinds are now widely accepted by scientific societies around the world (Lankton \& Mcknight, 2014). Traditional libraries are suffered from different limitations such as storage space while DLs maintain the capabilities to store much more data, simply because digital information needs very small physical space. In addition, the cost of having a digital library is less than traditional library one (Pomerantz \& Marchionini, 2007). A physical library needs to spend significant amount of budget for staff, book maintenance, rent, and additional books. DLs may reduce such unnecessary expenses and they may be more interested in adopting innovations in technology. 
Researchers do not need to come to campus for doing research and they may do their studies via distance (Smith, 1996; Shneiderman et al., 2000; Renda \& Straccia, 2005).

DLs provide more resources for users and they can increase availability to several students who may not be traditional patrons of a library, because of geographic location or organizational affiliation (Fox, 1999; Marchionini et al., 1998; Kling \& Elliott, 1994). These days, many graduate students try to do their searches using their mobile devices. Kim (2010) developed an integrated model designed to forecast a user's continuance behavior toward mobile data service (MDS) based on the expectationconfirmation model (ECM) and the theory of planned behavior (TPB). He examined some data collected from 207 different users who had prior experience with MDS using structure equation modeling. Results indicated that user satisfaction, perceived usefulness, perceived enjoyment, and perceived fee were essential parts of the formation of MDS continuance intention. The study provided some evidence that an integrated model could be a better explanatory power of MDS continuance compared with either model considered alone.

Bhattacherjee (2001) is believed to be the first who investigated cognitive beliefs and the effects influencing one's intention to continue using information systems (IS). He used Expectationconfirmation theory (Marshall et al., 1999; Jiang \& Klein, 2009) from the user behavior literature and combined with theoretical and empirical findings from prior IS usage studies to theorize a model of IS continuance.

Brown et al. (2008) discussed three theoretical models from met expectations research in the fields of organizational behavior and user psychology. Brown et al. (2011) proposed a model to investigate expectation confirmation in information systems based on the assimilation-contrast model and prospect theory, and recommended that both were required to account for the magnitude and direction of the deviations between experiences and expectations. Lin et al. (2005) studied the value of including "playfulness" in expectation-confirmation theory (ECT) when investigating continued use of a web site. They reported that perceived playfulness, confirmation to satisfaction, and perceived usefulness could all contribute substantially to the users' intent to reuse a web site and concluded that the extended ECT model could be an appropriate tool for the study of web site effects.

\section{The proposed study}

This paper presents an empirical investigation on usres' satisfaction based on the expectation disconfirmation paradigm theory. The study selects a sample of graduate students in Birjand University. The study uses a questionnaire developed by Isac and Rusu (2014). The sample size is calculated as follows,

$$
n=\frac{N \times z_{\alpha / 2}^{2} \times p \times q}{\varepsilon^{2} \times(N-1)+z_{\alpha / 2}^{2} \times p \times q},
$$

where $N$ is the population size, $p=1-q$ represents the yes/no categories, $z_{\alpha / 2}$ is CDF of normal distribution and finally $\varepsilon$ is the error term. Since we have $p=0.5, z_{\alpha / 2}=1.96$ and $N=2449$, the number of sample size is calculated as $n=332$. Fig. 1 demonstrates the structure of the proposed study.

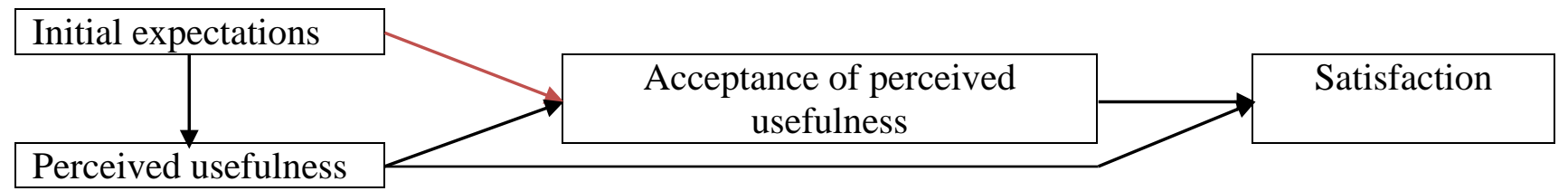

Fig. 1. The proposed study (Isac \& Rusu, 2014) 
In order to examine the effects of two factors of initial expectations and perceived usefulness on acceptance of perceived usefulness and the effect of acceptance of perceived usefulness on users' satisfaction, the study has designed of a questionnaire consists of four sections. The first part of the questionnaire is devoted to personal characteristics of the participants. The second part is associated with Initial expectations while the third part includes questions on perceived usefulness and the last part of the questionnaire is related to user's satisfaction. We first ask 40 university professors to verify the overall questionnaire. The content validity has been examined by gathering insights from 40 participants on the questionnaire. In addition, Freedman test has indicated that there was a meaningful relationship between the ranks of various factors (Asymp. Sig. $0.026<0.05$ ).

\section{The results}

The proposed study of this paper uses path analysis to verify the effects of various factors on users' satisfaction. The first question of survey tries to determine the factors influencing on users' satisfaction according to the expectation disconfirmation paradigm. Fig. 2 demonstrates the summary of our findings using path analysis.

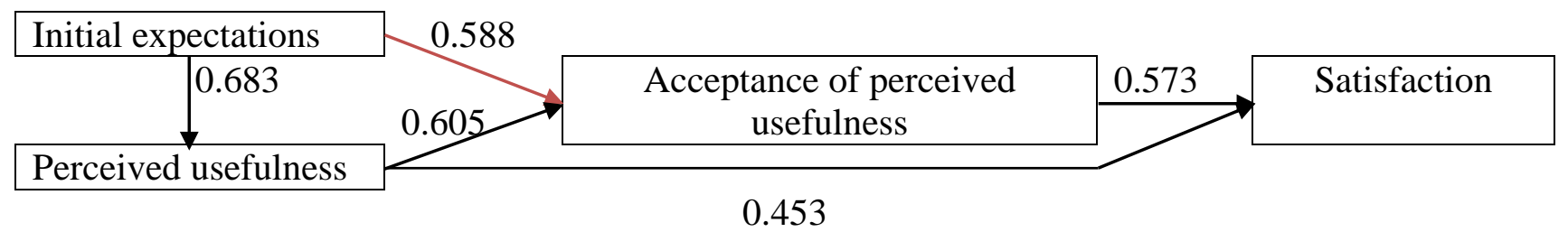

Fig. 2. The results of path analysis

As we can observe from the results of Fig. 2, initial expectations had the biggest direct impact on perceived usefulness and acceptance of perceived usefulness had the biggest positive impact on users' satisfaction.

The second question of the survey tries to determine the effects of various factors on users' satisfaction. To verify this, we have used rotated correlation matrix. Table 1 demonstrates the results of our survey.

Table 2

The summary of rotated correlation matrix

\begin{tabular}{lccc}
\hline & \multicolumn{1}{c}{ Factor } & \\
\cline { 2 - 3 } Perspective & $\begin{array}{c}\text { Initial } \\
\text { expectations }\end{array}$ & $\begin{array}{c}\text { Perceived } \\
\text { usefulness }\end{array}$ & $\begin{array}{c}\text { Acceptance of } \\
\text { perceived usefulness }\end{array}$ \\
\hline Other students' experiences & $0.755^{*}$ & & \\
Personal experiences & $0.830^{*}$ & & \\
Familiarity with digital library & $0.704^{*}$ & & \\
Number of hardware facilities & $0.827^{*}$ & & \\
Quality of hardware facilities & $0.543^{*}$ & & \\
Number of software facilities & $0.728^{*}$ & & \\
Availability of use from distance & $0.470^{*}$ & & \\
Desirability of frequent use & & $0.260^{*}$ & $0.446^{*}$ \\
Librarian representative & & $-0.035^{*}$ & $0.336^{*}$ \\
Perceived usefulness & & & \\
Offering to others & & & \\
${ }^{*}$ Sig.<0.05 & & & \\
\hline
\end{tabular}

According to the results of Table 1, all components of the survey are statistically meaningful when the level of significance is five percent. Personal experience seems to represent the highest correlation with 
initial expectations followed by existence of sufficient hardware facilities. In our survey, other student's experiences seem to influence positively on students' initial expectation as well.

\subsection{The relationship between perceived usefulness, initial expectations and acceptance of usefulness}

In order to verify the relationship between perceived usefulness, initial expectations and acceptance of usefulness, the study uses correlation matrix among these three variables. Table 3 demonstrates the results of the survey.

\section{Table 3}

The summary of correlation coefficients among perceived usefulness, initial expectations and acceptance of usefulness

\begin{tabular}{lccc}
\hline Factor & $\begin{array}{c}\text { Initial } \\
\text { expectations }\end{array}$ & $\begin{array}{c}\text { Perceived } \\
\text { usefulness }\end{array}$ & $\begin{array}{c}\text { Acceptance of } \\
\text { perceived usefulness }\end{array}$ \\
\hline Initial expectations & 1.00 & 0.683 & 0.588 \\
Perceived usefulness & 0.683 & 1.00 & 0.605 \\
Acceptance of perceived usefulness & 0.588 & 0.605 & 1.00 \\
\hline
\end{tabular}

Chi-Square $=33.562$ Sig. $=0.1$

According to the results of Table 3, there are some positive and meaningful relationships among three components of the survey. The highest correlation belongs to relationship between perceived usefulness and initial expectations.

\subsection{The relationship between perceived usefulness, acceptance of usefulness and users' satisfaction}

We have also used correlation coefficient matrix to verify the relationship between perceived usefulness, acceptance of usefulness and users' satisfaction and Table 4 demonstrates the results of our survey.

\section{Table 4}

The summary of correlation coefficients among perceived usefulness, acceptance of usefulness and users' satisfaction

\begin{tabular}{lccc}
\hline Factor & $\begin{array}{c}\text { Perceived } \\
\text { usefulness }\end{array}$ & $\begin{array}{c}\text { Acceptance of } \\
\text { perceived usefulness }\end{array}$ & Users' satisfaction \\
\hline Perceived usefulness & 1.00 & 0.605 & 0.453 \\
Acceptance of perceived usefulness & 0.605 & 1.00 & 0.573 \\
Users' satisfaction & 0.453 & 0.573 & 1.00 \\
\hline
\end{tabular}

The results of Table 4 also indicate that there were some positive and meaningful relationships among various components of the survey. The highest correlation is between perceived usefulness and acceptance of perceived usefulness.

\section{Conclusion}

Measuring the effects of various factors on improvement of digital libraries plays an essential role for development of knowledge among scientific societies. Many graduate students need to find their necessary research materials as quickly as possible. The findings of this study have indicated that when graduate students came under good perceived usefulness about digital libraries, they would be more interested in using digital libraries. The results have also indicated that perceived usefulness and personal experience had the highest impact on users' satisfaction in electronic library usage. In addition, there was a negative relationship between librarian representative and users’ satisfaction. 


\section{Acknowledgement}

The authors would like to thank the anonymous referees for constructive comments on earlier version of this paper. Special thanks goes to officials of the University of Birjand for cordially cooperating in accomplishment of this survey.

\section{References}

Akst, D. (2003). The digital library: Its future has arrived. Carnegie Reporter, 2(3), 4-8.

Bhattacherjee, A. (2001). Understanding information systems continuance: an expectationconfirmation theory. MIS Quarterly, 25(3), 351-370.

Brown, S. A., Venkatesh, V., Kuruzovich, J., Massey, A. P. (2008). Expectation confirmation: An examination of three competing models. Organizational Behavior and Human Decision Processes, 105(1), 52-66.

Brown, S. A., Venkatesh, V., \& Goyal, S. (2011). Expectation confirmation in technology use. Information Systems Research, 16(1), 1-14.

Cunningham, S. J., Reeves, N., \& Britland, M. (2003, May). An ethnographic study of music information seeking: implications for the design of a music digital library. In Proceedings of the 3rd ACM/IEEE-CS joint conference on Digital libraries (pp. 5-16). IEEE Computer Society.

Fox, E. A. (1999). The Digital Libraries Initiative: Update and Discussion. Bulletin of the American Society for Information Science, 26(1), 7-11.

Isac, F. L., \& Rusu, S. (2014). Theories of user's satisfaction and the operationalization of the expectation disconfirmation paradigm. Economic Series, University of Targu, 2 (1), 82-88.

Jiang, J. J., \& Klein, G. (2009). Expectation Confirmation Theory: Capitalizing on Descriptive Power. Handbook of Research on Contemporary Theoretical Models in Information Systems. (pp. 384-401). Hershey, PA: IGI Global.

Kim, B. (2010). An empirical investigation of mobile data service of continuance: Incorporating the theory of planned behavior into the expectation-confirmation model. Expert systems with applications, 37(1), 7033-7039.

Kling, R., \& Elliott, M. (1994). Digital library design for organizational usability. ACM SIGOIS Bulletin, 15(2), 59-70.

Lankton, N., Mcknight, H. (2014). Using expectation conformation theory to predict technology trust and usage continuance intentions. The Journal of Strategic Information Systems, 23(2), 128-145.

Lin, C. S., Wu, S., \& Tsai, J. (2005). Integrating perceived playfulness into expectation-confirmation model for web portal context. Information \& Management, 42(1), 683-693.

Marshall, C. C., Price, M. N., Golovchinsky, G., \& Schilit, B. N. (1999, August). Introducing a digital library reading appliance into a reading group. In Proceedings of the fourth ACM conference on Digital libraries (pp. 77-84). ACM.

Marchionini, G., Plaisant, C., \& Komlodi, A. (1998). Interfaces and tools for the Library of Congress national digital library program. Information processing \& management, 34(5), 535-555.

Marchionini, G., \& Geisler, G. (2002). The open video digital library. D-Lib Magazine, 8(12), 10829873.

Marshburn, D., \& Kirkwood-Mazhik, H. (2012). Expectation disconfirmation in software user acceptance testing: the mitigating effects of customer service management and relationship building. Proceedings of the Atlantic marketing association, 1(2), 299-302.

Pomerantz, J., \& Marchionini, G. (2007). The digital library as place. Journal of Documentation, 63(4), 505-533.

Renda, M. E., \& Straccia, U. (2005). A personalized collaborative digital library environment: a model and an application. Information Processing \& Management, 41(1), 5-21.

Saracevic, T. (2000). Digital library evaluation: Toward evolution of concepts. Library trends, 49(2), 350-369.

Schwartz, C. (2011). Understanding the role of expectation disconfirmation theory on IT outsourcing success. Doctoral dissertation, Louisiana State University. 
Shneiderman, B., Feldman, D., Rose, A., \& Grau, X. F. (2000, June). Visualizing digital library search results with categorical and hierarchical axes. In Proceedings of the fifth ACM conference on Digital libraries (pp. 57-66). ACM.

Smith, T. R. (1996). A digital library for geographically referenced materials. Computer, 29(5), 54-60. 